\title{
Effect of lower limb kinetic on carrying infant by hip seat carrier during high heel gait
}

\author{
Seung-Hyun Hyun, Che-Cheong Ryew* \\ Department of Kinesiology, College of Natural Science, Jeju National University, Jeju, Korea
}

While common characteristics between wearing of high heel between carrying an infant elevate height of center of gravity, it is not known what interaction effect influence to leg stiffness. The aim of the study is to investigate the effect of carrying infant by hip seat carrier on leg mechanics during high heel gait. Adult female $(n=9)$ and infant $(n=9)$ participated as subjects. Infant was positioned on rear of trunk as of wearing $6 \mathrm{~cm}$ of high heel shoe. Change of leg mechanics was analyzed with ground reaction force variables (1st peak vertical force [PVF], 2nd PVF, center of pressure [medial-lateral, anterior-posterior]), extrapolated center of mass (XCoM) theta, and leg stiffness. While carrying infant with wearing of high heel more increased 1st PVF, 2nd PVF, and leg stiff- ness than normal gait, and more decreased medial-lateral center of pressure and XCoM theta. High heel and carrying infant showed potential transformation of posture for securement of stability, which related with mechanism to decrease an impulse type. In conclusion, it is suggest that gait for long time in the condition may accumulate fatigue on leg and increase falling injury, so experts of clinics and exercise rehabilitation should understand the mechanism that could recommend guideline for exercise prescription on several problems.

Keywords: Infant carrying, High heel shoe, Lower limb kinetic, Leg stiffness, Extrapolated center of mass, Center of pressure

\section{INTRODUCTION}

Center of gravity (COG) was accelerated forwardly by three-dimensional external force during bipedal walking. Then the foot overloaded by body weight primarily absorbs and transfers ground reaction force (GRF) to whole body (Hyun et al., 2016). Thus human can adapt various surface environments with bipedal gait, but backpacking of bag and carrier in condition of increased velocity of COG before foot breaking may cause falling injury with difficulty of counteraction of angular momentum (Ko et al., 2017). Particularly women after baby delivering frequently carries an infant on baby carrier, type of which modifies impulse type transferring to leg and COG through increasing of load rate, leg stiffness, maximum vertical GRF and anterior-posterior GRF (Ryew and Hyun, 2018).

Also female accentuates more on fashion rather than foot function during gait, that is, on high heel shoe. During level walking by high heel shoe did not control efficiently the GRF due to re- stricted control capacity of coefficient of frictional force and therefore could suggest an inducement of muscle fatigue, heightening a possibility of sliding and falling due to decrease of frictional force (Blanchette et al., 2011; Hyun et al., 2016).

In addition wearing of high heel may cause possibility of lateral sprain of foot (Ebbeling et al., 1994; Foster et al., 2012), furthermore critical wound to infant. As this, whether the interaction effect between using of hip seat carrier for carrying of infant effectively and influence on modification of leg mechanics by wearing high heel for fashion after baby delivering is not known definitely.

Therefore the aim of the study is to analyze a modification of mechanics of leg on between wearing of high heel shoe and carrying infant during female's gait.

\section{MATERIALS AND METHODS}

\section{Subject}

Adult female experienced baby delivering $(\mathrm{n}=9)$ (mean age,
${ }^{*}$ Corresponding author: Che-Cheong Ryew (iD https://orcid.org/0000-0001-9473-3990 Department of Kinesiology, College of Natural Science, Jeju National University, 102 Jejudaehak-ro, Jeju 63243, Korea

Tel: +82-64-754-3588, Fax: +82-64-757-1752, E-mail: ryew@jejunu.ac.kr

Received: August 1, 2018 / Accepted: September 29, 2018
This is an Open Access article distributed under the terms of the Creative Commons Attribution Non-Commercial License (http://creativecommons.org/licenses/by-nc/4.0/) which permits unrestricted non-commercial use, distribution, and reproduction in any medium, provided the original work is properly cited. 


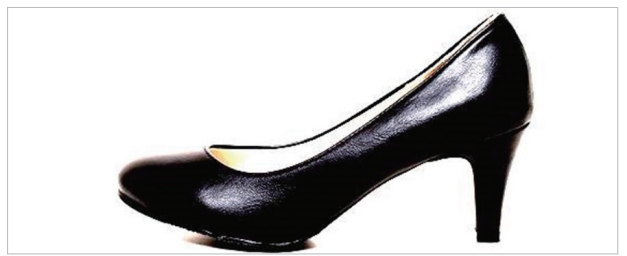

Fig. 1. High heel type with $6 \mathrm{~cm}$.

$27.88 \pm 2.71$ years; mean heights, $165.94 \pm 2.78 \mathrm{~cm}$; mean weights, $56.56 \pm 6.42 \mathrm{~kg}$ ) were selected as subjects. The subjects who consented on the preliminary detail explanation on the management of individual information, experimental procedure and method, and figure publication etc. participated in the experiment.

\section{Experimental procedure}

GRF system (AMTI-OR9-7, AMTI, Watertown, MA, USA) and camera (4ea.) (HDR/HDV 1980i, Sony Corp., Tokyo, Japan) fixed at 60 frame/sec camera speed and $1 / 500 \mathrm{sec}$ of exposure time set up at $5 \mathrm{~m}$ point on gait path of $10 \mathrm{~m}$ in line with horizontal plane. All participants wore $6 \mathrm{~cm}$ of high heel shoe (Fig. 1), performed repetitive prerehearsal of gait in order to adapt to static and dynamic movement. Thirty-one reflex markers attached on the subject's joints. Gait was performed randomly in condition of normal (no-load) and carrying an infant (under 1 full age, $\mathrm{n}=9$; mean weights, $10.93 \pm 3.56 \mathrm{~kg}$ ) using rear-trunk carrier (Ergobaby Carrier Omni 360, Ergobaby, Vietnam) (Fig. 2). Only 1 trial successful after gait over 3 times was selected for analysis.

\section{Definition of analysis phase}

Analyzed variables consisted of 1 st peak vertical force, 2 nd peak vertical force, center of pressure (medial-lateral COP, anterior-posterior COP), extrapolated center of mass (XCoM), and leg stiffness.

Variables of COP were analyzed on maximal trajectory in medial-lateral and anterior-posterior direction of right foot. XCoM theta was calculated from medial-lateral inclined degree on XCoM coordinates (medial-lateral XCoM, vertical CoM) and COP coordinates (medial-lateral COP, $\mathrm{Z}$ axis [0]) on medial-lateral plane during supporting phase of right foot (Hof et al., 2007).

Leg stiffness (Silder et al., 2015) was calculated from normalized vertical GRF $\left(F_{\text {max }}\right)$ divided by change rate $\left(\left(l_{o}-l_{\text {min }}\right) / l_{o}\right)$ of $100 \%$ normalized leg length $\left(l_{o}\right)$. And then $l_{\text {min }}$ of leg length was set at $F_{\text {max }}$.

$$
K_{\text {leg }}=\frac{F_{\max }}{\left(l_{o}-l_{\min }\right) / l_{o}}
$$

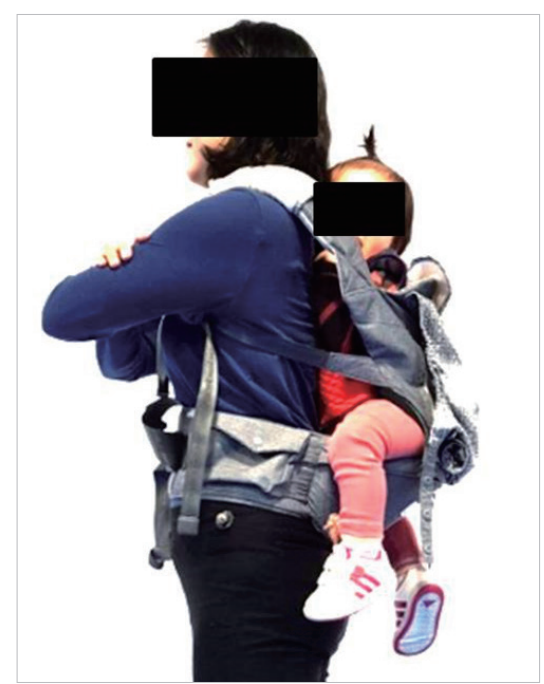

Fig. 2. Carrying infant during gait. Informed consent was obtained from the subjects for the publication.

\section{Analysis and process of data}

The average and the standard deviation on the calculated variables were obtained using IBM SPSS Statistics ver. 21.0 (IBM Co., Armonk, NY, USA), and was performed repeated measures twoway analysis of variance and performed the post hoc test (Duncan) at $(P<0.05)$ in case of significant level respectively.

\section{RESULTS}

Analyzed result of GRF variables according to walking conditions and wearing heel shoe during gait was as (Table 1). The 1st PVF showed significant differences statistically according to the wearing heel shoe and walking conditions, but interaction effect between walking conditions and wearing heel shoe did not show. The 2nd PVF showed significant differences statistically according to the walking conditions, while change with wearing heel shoe and interaction effect between wearing heel shoe and walking conditions did not show.

Medial-lateral COP showed significant differences statistically according to the heel heights and walking conditions, but interaction effect between walking conditions and wearing heel shoe did not show. Anterior-posterior COP did not show significant differences statistically according to the wearing heel shoe and walking conditions during gait.

Analyzed result of leg stiffness and XCoM theta according to walking conditions and heel heights during gait was as (Table 2). $\mathrm{XCoM}$ theta showed significant differences statistically in case of wearing heel shoe, while change with walking conditions and in- 
Table 1. Results of ground reaction force variables according to the walking conditions during gait

\begin{tabular}{|c|c|c|c|c|c|c|c|}
\hline \multirow{2}{*}{ Section } & \multirow{2}{*}{$\begin{array}{l}\text { Walking conditions } \\
\text { (W) }\end{array}$} & \multicolumn{3}{|c|}{ Heel height (H) } & \multirow{2}{*}{ Source } & \multirow{2}{*}{$F$} & \multirow{2}{*}{$P$-value } \\
\hline & & Barefoot & $6 \mathrm{~cm}$ with heel & Total average & & & \\
\hline \multirow[t]{3}{*}{ 1st peak vertical force (N/BW) } & Normal & $1.16 \pm 0.06$ & $1.20 \pm 0.09$ & $1.18 \pm 0.07$ & $\mathrm{H}$ & 11.205 & $0.004^{* *}$ \\
\hline & Carrier of infant & $1.30 \pm 0.14$ & $1.44 \pm 0.12$ & $1.37 \pm 0.15$ & W & 18.657 & $0.001^{* * *}$ \\
\hline & Total average & $1.12 \pm 0.13$ & $1.32 \pm 0.16$ & $1.27 \pm 0.16$ & $\mathrm{H} \times \mathrm{W}$ & 3.420 & 0.083 \\
\hline \multirow[t]{3}{*}{ 2nd peak vertical force (N/BW) } & Normal & $1.17 \pm 0.12$ & $1.20 \pm 0.07$ & $1.18 \pm 0.10$ & $H$ & 4.283 & 0.055 \\
\hline & Carrier of infant & $1.27 \pm 0.06$ & $1.39 \pm 0.17$ & $1.34 \pm 0.13$ & W & 12.596 & $0.003^{* *}$ \\
\hline & Total average & $1.22 \pm 0.11$ & $1.30 \pm 0.16$ & $1.26 \pm 0.14$ & $\mathrm{H} \times \mathrm{W}$ & 1.097 & 0.311 \\
\hline \multirow[t]{3}{*}{ Medial-lateral center of pressure $(\mathrm{cm})$} & Normal & $3.07 \pm 1.39$ & $2.28 \pm 0.49$ & $2.68 \pm 1.09$ & $\mathrm{H}$ & 8.093 & $0.012^{*}$ \\
\hline & Carrier of infant & $2.28 \pm 0.49$ & $1.71 \pm 0.45$ & $2.00 \pm 0.54$ & W & 5.116 & $0.038^{*}$ \\
\hline & Total average & $2.68 \pm 1.09$ & $2.00 \pm 1.93$ & $2.34 \pm 0.91$ & $\mathrm{H} \times \mathrm{W}$ & 0.105 & 0.657 \\
\hline \multirow[t]{3}{*}{ Anterior-posterior center of pressure $(\mathrm{cm})$} & Normal & $19.83 \pm 1.23$ & $18.42 \pm 2.31$ & $19.12 \pm 1.93$ & $H$ & 1.415 & 0.252 \\
\hline & Carrier of infant & $21.50 \pm 3.21$ & $20.96 \pm 3.58$ & $21.23 \pm 3.31$ & W & 4.427 & 0.052 \\
\hline & Total average & $20.66 \pm 2.51$ & $19.69 \pm 3.20$ & $20.18 \pm 2.88$ & $\mathrm{H} \times \mathrm{W}$ & 0.287 & 0.599 \\
\hline
\end{tabular}

Values are presented as mean \pm standard deviation.

$\mathrm{H}$, main effect of the heel height; $\mathrm{W}$, main effect of the walking condition; $\mathrm{H} \times \mathrm{W}$, interaction.

${ }^{*} P<0.05$. ${ }^{* *} P<0.01$. ${ }^{* *} P<0.001$.

Table 2. Results of leg stiffness and XCoM theta according to the walking conditions during gait

\begin{tabular}{|c|c|c|c|c|c|c|c|}
\hline \multirow{2}{*}{ Section } & \multirow{2}{*}{$\begin{array}{l}\text { Walking conditions } \\
\text { (W) }\end{array}$} & \multicolumn{3}{|c|}{ Heel height (H) } & \multirow{2}{*}{ Source } & \multirow{2}{*}{$F$} & \multirow{2}{*}{$P$-value } \\
\hline & & Barefoot & $6 \mathrm{~cm}$ with heel & Total average & & & \\
\hline \multirow[t]{3}{*}{ XCoM theta $\left({ }^{\circ}\right)$} & Normal & $6.98 \pm 2.35$ & $4.99 \pm 1.30$ & $5.98 \pm 2.11$ & $\mathrm{H}$ & 15.439 & $0.001^{* * *}$ \\
\hline & Carrier of infant & $6.01 \pm 2.08$ & $4.20 \pm 2.49$ & $5.10 \pm 2.42$ & W & 1.019 & 0.328 \\
\hline & Total average & $6.49 \pm 2.21$ & $4.59 \pm 1.95$ & $5.54 \pm 2.28$ & $\mathrm{H} \times \mathrm{W}$ & 0.031 & 0.861 \\
\hline \multirow[t]{3}{*}{ Leg stiffness (dimensionless) } & Normal & $13.08 \pm 2.61$ & $18.65 \pm 5.33$ & $15.86 \pm 4.96$ & H & 35.641 & $0.001^{* * *}$ \\
\hline & Carrier of infant & $25.70 \pm 5.68$ & $31.80 \pm 7.55$ & $28.75 \pm 7.20$ & W & 27.839 & $0.001^{* * *}$ \\
\hline & Total average & $19.39 \pm 7.78$ & $25.23 \pm 9.27$ & $22.31 \pm 8.94$ & $\mathrm{H} \times \mathrm{W}$ & 0.075 & 0.787 \\
\hline
\end{tabular}

Values are presented as mean \pm standard deviation.

XCoM, extrapolated centre of mass; $\mathrm{H}$, main effect of the heel height; $\mathrm{W}$, main effect of the walking condition; $\mathrm{H} \times \mathrm{W}$, interaction ${ }^{* * *} P<0.001$.

teraction effect between wearing heel shoe and walking conditions did not show.

Leg stiffness showed significant differences statistically in case of wearing heel shoe and walking conditions, but interaction effect between walking conditions and heel heights did not show.

\section{DISCUSSION}

Baby carrier was manufactured for not only maintaining close distance between mother and infant but also providing convenience. While it is effective utility for carrying infant, interaction effect by wearing high heel shoe during gait is not known.

When compared main effect on wearing high heel shoe during gate of women, wearing high heel shoe showed more increased 1st PVF, leg stiffness than bare foot walking, decreased range of $\mathrm{XCoM}$ theta, and medial-lateral COP. Also knee joint angle during gait more increased relative to increase of height of high heel (Kerrigan et al., 1998; Mika et al., 2012; Opila-Correia, 1990). But clear physical modification observed by wearing high heel shoe was plantar flexion of foot, which increased rigidity along with range of motion of ankle joint (Csapo et al., 2010; Ebbeling et al., 1994).

Leg stiffness is due to rigidity of muscle and joint uncontrollability (Greene and McMahon, 1979), which has close relation between stability contribution and occurrence of injury (Granata et al., 2002). When analyzed at PVF of initial touch-down in the study, leg stiffness increase was due to 1st PVF occurred before occurrence of motion of leg and motion of rigid leg. Also range of medial-lateral COP in high heel shoe showed decreased pattern than bare foot gait. Medial-lateral change of COP was due to fast pronation for impact absorption at initial touch-down of foot segment, which utilize different strategy each other (Chiu et al., 
2013). Thus it can be considered that wearing high heel shoe can modify potentially movement of leg and whole body posture.

When compared main effect on carrying infant during gait of women, carrying infant more increased 1st PVF, 2nd PVF, and leg stiffness than normal gait, and decreased medial-lateral COP, which was due to added weight of infant and was similar with result of Ryew and Hyun (2018) which increased impulse type during carrying infant.

Also they reported when carried on rear of trunk, stability can be secured by altering mechanic function (impulse type), decreasing pattern of medial-lateral COP in the study was considered to be mechanism for securement of dynamic stability of gait. But straight path of medial-lateral COP meant the pattern which could not maintain the forward momentum of COG, which might result in increased muscle fatigue of leg and more requirement of an active component (muscle force, 2nd PVF) at propulsive phase.

Interaction effect relative to wearing high heel shoe and carrying infant was not, while carrying infant in condition of $6 \mathrm{~cm}$ of high heel shoe most increased in variable of 1st PVF, 2nd PVF, and leg stiffness, but decreased in medial-lateral COP. Characteristics of narrowed box of foot toe, rigid heel cap and curve pattern confined the natural movement of foot (Cronin, 2014). Because also balance and propulsive force for active exercise by one sided leg on ground during repetitive gait cycle is essential (Cronin, 2014), interaction effect between $6 \mathrm{~cm}$ of high heel and carrying infant may has influence on occurring of potential modification of posture.

Posture modification was due to mechanism counteracting an impulse type, but Injury occurrence of leg and possibility of falling injury during carrying infant for long time and with high heel shoe may increase. Thus experts of clinic and exercise rehabilitation need clearer understand an interaction effect between wearing high heel shoe and carrying infant, and an accurate measurement on negative effect and mechanics of leg during gait.

\section{CONFLICT OF INTEREST}

No potential conflict of interest relevant to this article was reported.

\section{REFERENCES}

Blanchette MG, Brault JR, Powers CM. The influence of heel height on utilized coefficient of friction during walking. Gait Posture 2011;34: 107-110.

Chiu MC, Wu HC, Chang LY. Gait speed and gender effects on center of pressure progression during normal walking. Gait Posture 2013;37:4348.

Cronin NJ. The effects of high heeled shoes on female gait: a review. J Electromyogr Kinesiol 2014;24:258-263.

Csapo R, Maganaris CN, Seynnes OR, Narici MV. On muscle, tendon and high heels. J Exp Biol 2010;213(Pt 15):2582-2588.

Ebbeling CJ, Hamill J, Crussemeyer JA. Lower extremity mechanics and energy cost of walking in high-heeled shoes. J Orthop Sports Phys Ther 1994;19:190-196.

Foster A, Blanchette MG, Chou YC, Powers CM. The influence of heel height on frontal plane ankle biomechanics: implications for lateral ankle sprains. Foot Ankle Int 2012;33:64-69.

Granata KP, Padua DA, Wilson SE. Gender differences in active musculoskeletal stiffness. Part II. Quantification of leg stiffness during functional hopping tasks. J Electromyogr Kinesiol 2002;12:127-135.

Greene PR, McMahon TA. Reflex stiffness of man's anti-gravity muscles during kneebends while carrying extra weights. J Biomech 1979;12: 881-891.

Hof AL, van Bockel RM, Schoppen T, Postema K. Control of lateral balance in walking. Experimental findings in normal subjects and aboveknee amputees. Gait Posture 2007;25:250-258.

Hyun SH, Kim YP, Ryew CC. Effect on the parameters of the high-heel shoe and transfer time of ground reaction force during level walking. J Exerc Rehabil 2016;12:451-455.

Kerrigan DC, Todd MK, Riley PO. Knee osteoarthritis and high-heeled shoes. Lancet 1998;351:1399-1401.

Ko YC, Ryew CC, Hyun SH. Relationship among the variables of kinematic and tilt angle of whole body according to the foot trip during gait. J Exerc Rehabil 2017;13:117-121.

Mika A, Oleksy Ł, Mika P, Marchewka A, Clark BC. The influence of heel height on lower extremity kinematics and leg muscle activity during gait in young and middle-aged women. Gait Posture 2012;35:677-680.

Opila-Correia KA. Kinematics of high-heeled gait. Arch Phys Med Rehabil 1990;71:304-309.

Ryew CC, Hyun SH. Effect of slipper wearing and carrying positions of infant on dynamic stability and kinetic variable during level walking. J Exerc Rehabil 2018;14:699-703.

Silder A, Besier T, Delp SL. Running with a load increases leg stiffness. J Biomech 2015;48:1003-1008. 